\title{
Safety and efficacy of entecavir for the treatment of chronic hepatitis B
}

\author{
This article was published in the following Dove Press journal: \\ Infection and Drug Resistance \\ 2 February 201I \\ Number of times this article has been viewed
}

\section{Melissa Osborn \\ Department of Medicine, Division of Infectious Diseases, Emory University School of Medicine, Atlanta, GA, USA}

Correspondence: Melissa Osborn Emory University Hospital Midtown, 550 Peachtree St, 7th Floor Medical Office Tower, Atlanta, GA 30308, USA

$\mathrm{Tel}+\mathrm{I} 4046868 \mathrm{II} 4$

Fax + I 404686484 |

Email mkosbor@emory.edu
Abstract: Entecavir is a cyclopentyl deoxyguanosine analog that was approved for the treatment of the hepatitis B virus (HBV) in 2005. In Phase III trials, it showed potent HBV suppression with drops of 6- to 7-log copies/mL in HBV DNA at 1 year. In addition, rates of genotypic resistance in nucleos(t)ide-naïve patients are low, reaching only $1.2 \%$ after 6 years. Safety and efficacy have been established in compensated cirrhosis and HIV-coinfected patients. Studies in decompensated cirrhosis also show efficacy. Because of potent viral suppression and a large genetic barrier to resistance, entecavir is now a first-line choice in most HBV treatment guidelines and has become an integral part of the HBV treatment armamentarium.

Keywords: hepatitis B, therapy, entecavir

\section{Introduction}

During the past decade, four new drugs (adefovir, entecavir, telbivudine, and tenofovir) have been approved for the treatment of chronic hepatitis B virus (HBV), joining lamivudine as options for treatment. These new additions to the HBV arsenal have made decisions about treatment more complex. It has become increasingly important for treating physicians to understand the benefits and limitations of each agent as they decide on an initial or salvage regimen. This review will describe the efficacy of entecavir compared with other available drugs, as well as safety and resistance patterns. These issues are important to consider for drug sequencing in patients with chronic HBV.

\section{Natural history of hepatitis B}

Over 350 million people worldwide are chronically infected with HBV. ${ }^{1}$ The burden of disease is largely geographic, with South-East Asia and Sub-Saharan Africa being endemic. ${ }^{1}$ In these areas, transmission is primarily vertical or during childhood, where most infections go on to chronicity. ${ }^{2}$ In nonendemic areas, such as western Europe and the US, transmission is primarily sexual and occurs in early adulthood. When acquired later during life in this situation, $95 \%$ of acute HBV cases resolve spontaneously. ${ }^{2}$ Universal vaccination of infants in both endemic and nonendemic areas will no doubt change this epidemiology over the coming decades.

Once chronicity is established, the patient may undergo a period of immunotolerance, where HBV DNA levels are extremely high yet aspartate aminotransferase (AST) and alanine aminotransferase (ALT) levels are normal. ${ }^{3}$ There is little to no inflammation present in the liver. In endemic areas, the immunotolerant period may last years, into the third decade of life. In nonendemic areas, however, the immunotolerant period 
generally is so short as to not be recognized. Following the immunotolerant period is the time of immune clearance, or active chronic HBV. HBV DNA levels are still high, and ALT and AST levels also become elevated as an indication of active inflammation of the hepatic tissue. Hepatitis B e antigen ( $\mathrm{HBe} A g)$ is positive. If the patient maintains this state for longer than 6 months (distinguishing acute HBV from chronic HBV), treatment is indicated.

Some patients will pass through the immune clearance phase without treatment and become inactive carriers of $\mathrm{HBV}$, where HBV surface antigen remains positive but $\mathrm{HBeAg}$ becomes negative and hepatitis $\mathrm{B}$ e antibody (anti-HBe) develops. The HBV DNA levels during this time are low or undetectable, and AST and ALT levels are normal. In many cases, this carrier state persists long term, but, in others, HBV can reactivate as chronic "e-antigen-negative" HBV. ${ }^{3}$ HBV DNA levels again rise, AST and ALT levels become elevated, and treatment is indicated once again. This is a later stage in the natural history of disease and can progress to cirrhosis more quickly. Typically, e-antigen-negative HBV occurs due to a mutation in the precore region that prohibits e-antigen from being produced. ${ }^{5}$

The endpoints for studies of therapeutics in HBV have been standardized according to a workshop convened by the National Institutes of Health. ${ }^{6}$ New agents are studied separately in e-antigen-positive patients and e-antigen-negative patients. For both subgroups, endpoints include virologic suppression (drop in HBV DNA), biochemical response (normalization of ALT), and histological response (decrease in Knodell necroinflammatory score by at least two points with no worsening of fibrosis scores). For $\mathrm{HBeAg}$-positive patients, additional endpoints of $\mathrm{HBeAg}$ loss and $\mathrm{HBeAg}$ seroconversion (development of anti-HBe) are also included. All of these endpoints are surrogate endpoints. More longterm follow-up is needed to determine whether these agents improve mortality or decrease development of end-stage liver disease or hepatocellular carcinoma (HCC).

\section{Mechanism and pharmacokinetics of entecavir}

All HBV therapies interrupt HBV replication by acting as nucleos(t)ide analogs. The chemical structure of lamivudine is $2^{\prime} 3^{\prime}$-dideoxy-3'-thiacytidine. Adefovir is a nucleotide ana$\log$ of adenosine monophosphate. Tenofovir is structurally similar to adefovir. Telbivudine is a 1-nucleoside analog of deoxythymidine.

Entecavir is a cyclopentyl guanosine nucleoside analog that has selective activity against the $\mathrm{HBV}$ polymerase. ${ }^{7}$ It is efficiently phosphorylated to its active triphosphate form by host cellular kinases. ${ }^{8}$ Entecavir blocks HBV replication at three essential steps: priming of the HBV polymerase, elongation of the DNA strand via reverse transcription, and DNA-dependent plus-strand DNA synthesis and polymerization. ${ }^{9}$ In contrast, lamivudine shows negligible effects on the priming reaction.

In pharmacokinetic studies in healthy subjects, peak plasma concentrations of entecavir were reached in $0.5-1.5$ hours, with steady state reached after 6-10 days of once-daily administration. ${ }^{7}$ The intracellular half-life is approximately 15 hours. It is predominantly excreted by the kidney with urinary recovery of the unchanged drug at steady state ranging from $62 \%$ to $73 \%$ of the administered dose. ${ }^{7}$ Because of this, entecavir requires dosage adjustment for patients with creatinine clearance less than $50 \mathrm{~mL} / \mathrm{min}$, including those on dialysis. ${ }^{7}$ No dosage adjustment is required in liver disease. Pharmacokinetic studies have shown that entecavir is not a substrate, inhibitor, or inducer of the cytochrome P450 enzyme system, and therefore the pharmacokinetics of entecavir are unlikely to be affected by coadminstration of agents that are metabolized by, inhibit, or induce these enzymes. ${ }^{7}$

\section{Clinical studies of efficacy}

Phase I dose-ranging studies of entecavir demonstrated rapid and potent dose-related virologic suppression of HBV DNA. ${ }^{10,11}$ Because of shared resistance mutations between entecavir and lamivudine, clinical trials evaluated its use in both nucleos(t)ide-naïve patients and lamivudine-refractory patients. Efficacy was reduced in lamivudine-refractory patients harboring mutations in the tyrosine-methionineaspartate-aspartate (YMDD) motif of the HBV polymerase; thus, a higher dosage of $1 \mathrm{mg}$ daily was selected for development in these patients, compared with $0.5 \mathrm{mg} /$ day for nucleos(t)ide-naïve patients.

Two multinational Phase III trials were conducted among nucleos(t)ide-naïve patients in $\mathrm{HBeAg-positive} \mathrm{patients}{ }^{12}$ and HBeAg-negative patients, ${ }^{13}$ both compared with lamivudine $100 \mathrm{mg}$ daily. A Phase III trial was also carried out in China in a mixed population of both $\mathrm{HBe} A g$-positive and $\mathrm{HBe} A g$-negative patients. ${ }^{14} \mathrm{~A}$ smaller Phase III study compared entecavir with adefovir in patients with baseline HBV DNA levels $>8 \mathrm{log}$ copies $/ \mathrm{mL} .{ }^{15}$ Among HBeAg-positive patients, results at 48 weeks were similar across all studies with $68 \%-89 \%$ of patients achieving ALT normalization, and 58\%-74\% having an undetectable HBV DNA by sensitive polymerase chain reaction (PCR) assay (Table 1). The mean drop in HBV DNA over 48 weeks was 6-7 log copies $/ \mathrm{mL}$. On all of these parameters, 


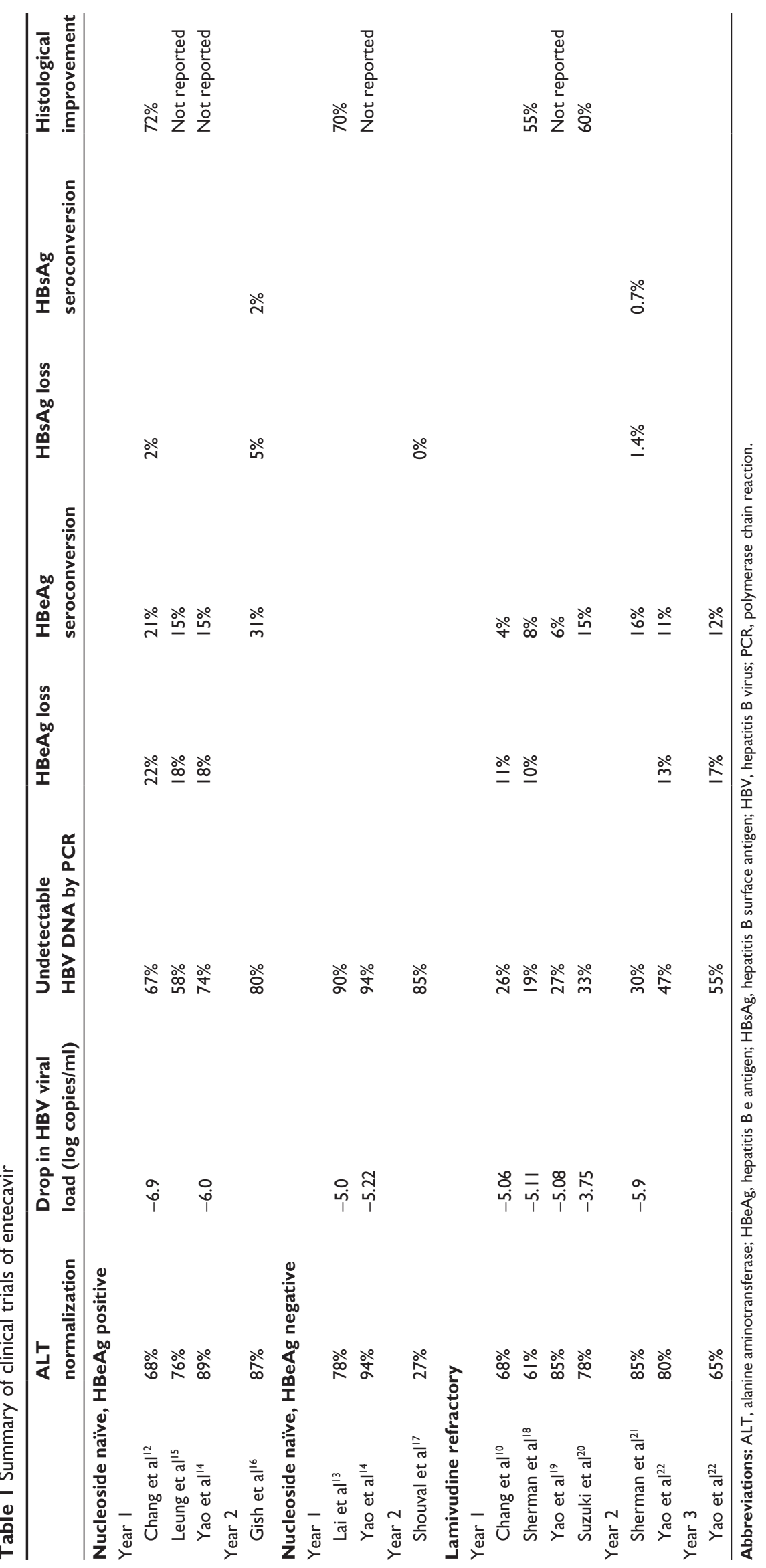


entecavir outperformed the comparator drug. Rates of $\mathrm{HBeAg}$ loss were $18 \%-22 \%$ and $\mathrm{HBeAg}$ seroconversion $15 \%-21 \%$, which were no different from rates seen in the lamivudine arms of the trial. Only one study reported on histologic response (its primary endpoint), with $72 \%$ of entecavir-treated patients responding favorably. ${ }^{12}$

Results at 48 weeks were similar among nucleoside-naïve HBeAg-negative patients, though the number of patients treated in the Chinese study was small $(\mathrm{n}=33) .{ }^{13,14}$ High rates of ALT normalization (78\%-94\%), undetectable HBV DNA by PCR assay (90\%-94\%), and histologic response (70\%) were seen. The mean drop in HBV DNA was approximately $5 \log$ copies/mL.

Phase II and III studies in the more difficult-to-treat lamivudine-refractory population were completed in multinational ${ }^{12,18}$ and Asian cohorts. ${ }^{19,20}$ Week 48 HBV DNA suppression was not as robust as seen in naïve patients, with mean decreases of about $5 \log$ copies/mL. ALT normalization was seen in $61 \%-85 \%$ of patients, and HBV DNA undetectability by PCR assay in just $19 \%-33 \%$ of subjects at the end of 1 year. Among $\mathrm{HBe} A g-$ positive patients, $\mathrm{HBeAg}$ loss was seen in 10\%-11\%, and $\mathrm{HBeAg}$ seroconversion in 4\%-8\%. Histologic responses were seen in $55 \%-60 \%$ of subjects. ${ }^{18,20}$

The design of the entecavir trials makes determinations of efficacy beyond 48 weeks confusing. In most trials, patients who were classified as "responders" (in HBeAgpositive patients: HBV DNA $<0.7 \mathrm{mEq} / \mathrm{mL}[\sim 700,000$ copies/mL], loss of $\mathrm{HBeAg}$; in $\mathrm{HBeAg}$-negative patients: HBV DNA $<0.7 \mathrm{mEq} / \mathrm{mL}$ ) were removed from the study drug at 48 weeks and monitored off therapy for sustained response without the now standard period of consolidation therapy following $\mathrm{HBeAg}$ seroconversion. ${ }^{23}$ Nonresponders (HBV DNA $>0.7 \mathrm{mEq} / \mathrm{mL}$ at week 48 ) were also discontinued from therapy. Therefore, those continuing on entecavir for 2 years and beyond represent a biased cohort of patients from which conclusions regarding entecavir efficacy must be made with caution. However, published data suggest that entecavir maintains virologic suppression and ALT normalization through up to 5 years of treatment, with additional cumulative $\mathrm{HBeAg}$ seroconversion and a small chance of HBV surface antigen (HBsAg) loss. 16,17,21,22,24

Compared with other available nucleos(t)ide analogs, entecavir achieves more potent HBV DNA suppression than all agents except perhaps tenofovir, which is equivalent. HBeAg clearance and HBeAg seroconversion are comparable with lamivudine. As with most oral agents, surface antigen loss is rare. Comparative efficacies of available agents at 1 year are shown in Table 2 .

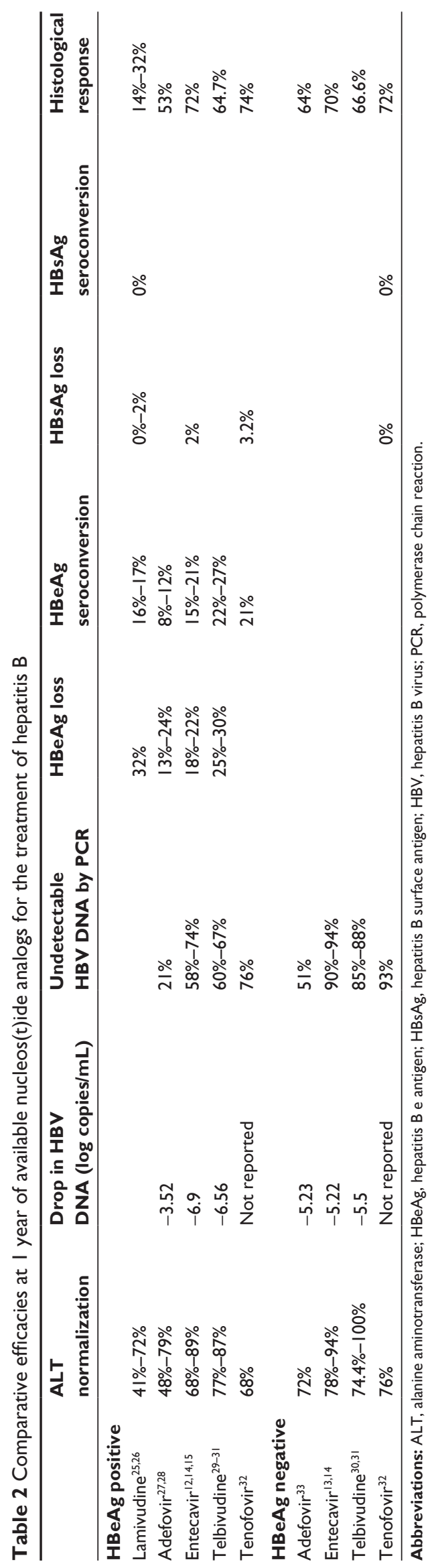




\section{Entecavir resistance}

One disadvantage of nucleos(t)ide analogs is development of antiviral resistance with prolonged use. Resistance is accompanied by virologic and biochemical breakthrough, and, in rare cases, hepatic decompensation and death. ${ }^{34,35}$ Rates of lamivudine resistance exceed $70 \%$ by year 4 of treatment, ${ }^{36}$ limiting its usefulness for first-line therapy. Resistance rates for adefovir and telbivudine are lower, yet still clinically significant (Figure 1). Tenofovir resistance has not yet been well defined but appears to be rare, as no signature mutation has been defined and genotypic resistance through 4 years of therapy has not been reported. ${ }^{41}$

Resistance to HBV antivirals is conferred by mutations in the HBV polymerase, which render the agent ineffective. For lamivudine, the signature mutation is a change in the reverse transcriptase at position 204 from methionine to valine or isoleucine (rtM204V/I) ${ }^{43}$ The rtM204I mutation also confers resistance to telbivudine.$^{42}$ Lamivudine-resistant patients may develop a compensatory mutation at position 180 from leucine to methionine ( $\mathrm{rtL} 180 \mathrm{M})$, which restores viral fitness. Adefovir does not show cross-resistance with lamivudine or telbivudine, with its signature resistance mutations a change from asparagine to threonine at position 236 $(\mathrm{rtN} 236 \mathrm{~T})^{44}$ or alanine to valine or threonine at position 181 $\left(\right.$ rtA181V/T) ${ }^{45}$

Entecavir resistance is unique because it requires up to three mutations for full resistance to develop. ${ }^{46}$ The rtM204V/I mutation, lamivudine's signature mutation, is necessary but not sufficient for entecavir resistance, causing an 8- to 10-fold decrease in susceptibility to entecavir compared with wild-type HBV. Additional mutations at positions rtI169, rtT184, rtS202, and rtM250 confer additional decreases in entecavir susceptibility. ${ }^{46,47}$ These mutations alone have only a minimal impact on entecavir efficacy, but in the presence of an rtM204 mutation, the addition of one of these mutations leads to a 10 - to 250 -fold decrease in entecavir susceptibility and two mutations to a 500 - to 1000 -fold decrease. ${ }^{46,47}$

The large genetic barrier to resistance has predictably led to low observed rates of clinical genotypic entecavir resistance in trials of nucleos $(\mathrm{t})$ ide-naïve $\mathrm{HBV}$ patients. In the registration trials of entecavir, rates of genotypic resistance after 1 year were $0 \%$ in both $\mathrm{HBeAg}$-positive and $\mathrm{HBeAg}$-negative patients. ${ }^{12,13} \mathrm{~A}$ long-term resistance cohort from these trials has demonstrated that, after 4 years, cumulative resistance in naïve patients was $0.8 \%$ and, after 6 years, $1.2 \% .{ }^{37}$ Cumulative genotypic resistance rates among lamivudine-refractory patients are much higher: $6 \%, 15 \%, 36 \%, 47 \%, 51 \%$, and $57 \%$ at years $1-6$, respectively. ${ }^{37}$ Although entecavir has been studied in lamivudine-refractory patients, its use as a salvage drug in this setting is generally not recommended when other options are available, because of these higher resistance rates. This demonstrates the superiority of entecavir when used as a first-line agent rather than following lamivudine failure, and highlights the importance of considering antiviral sequencing when selecting initial HBV therapy.

\section{Special populations Advanced fibrosis, cirrhosis, and transplanted patients}

Approximately $15 \%$ of the subjects enrolled in the registration trials of entecavir had advanced fibrosis, defined as

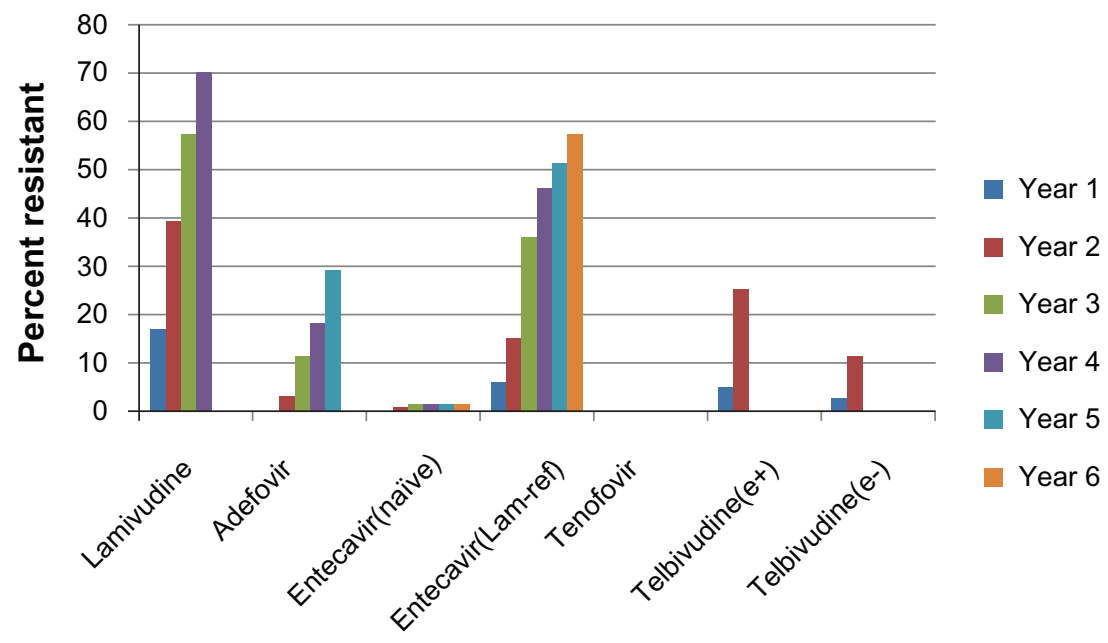

Figure I Resistance rates of available nucleos(t)ide analogs in hepatitis B patients. Note that no tenofovir resistance has been seen through 4 years of follow-up. ${ }^{31,36-42}$ Abbreviations: e+, hepatitis B e-antigen positive; e-, hepatitis B e-antigen negative; lam-ref, lamivudine refractory. 
an Ishak score of 4-6. All patients had compensated liver disease. Results in this subgroup of patients were published separately. ${ }^{48}$ For all endpoints examined in the parent studies, subjects with advanced fibrosis achieved comparable efficacy with the overall study population, including $\mathrm{HBeAg}$-positive, HBeAg-negative, and lamivudine-refractory populations. Up to $59 \%$ of patients experienced an improvement in Ishak fibrosis score, which was better than that seen in the study population at large. Patients with advanced fibrosis or cirrhosis did not experience any more adverse events than the overall study population. No patient discontinued entecavir due to adverse events. There was a single ALT flare in the entecavir group. All deaths in the entecavir arm during the trial occurred in the subgroup with advanced fibrosis or cirrhosis, but no death was deemed related to study drug. One patient died from a gastrointestinal bleed secondary to a splenic lymphoma, one from hepatocellular carcinoma, and one from multiorgan failure from diabetes mellitus and cirrhosis. $^{48}$

Experience with entecavir in decompensated cirrhosis has shown improvements in Child-Turcotte-Pugh (CTP) scores (from 8.1 to 6.6) and Model for End-stage Liver Disease (MELD) scores (from 11.1 to 8.8) after 1 year of therapy. ${ }^{49}$ In this single-center study, all patients were nucleos(t)ide naïve, as well as naïve to interferon. Compared with patients with compensated liver disease, those with decompensated cirrhosis had comparable rates of undetectable HBV DNA at month 12 (89.1\% versus $78.5 \%, P=0.104)$, HBeAg seroconversion (22.2\% versus $24.4 \%, P=0.812$ ), HBeAg loss (48.1\% versus $41.1 \%, P=0.512$ ), and ALT normalization (76.4\% versus $75.0 \%, P=0.535) .{ }^{49}$ There were no virologic breakthroughs on therapy. The cumulative incidence of mortality was $17 \%$ and the cumulative incidence of HCC or liver transplant was $6.9 \%$ among the decompensated cirrhotics, but no control group was reported.

Entecavir has also been compared with adefovir in a Phase IIIb study in subjects with evidence of hepatic decompensation. ${ }^{50}$ At baseline, the mean HBV DNA in the entecavir group was $7.53 \log$ copies/mL, mean MELD 17.1, and mean CTP score 8.81. Thirty-six percent of subjects were lamivudine resistant, and 54\% were HBeAg positive. In an interim analysis of the first 100 patients to complete 96 weeks of treatment, entecavir had a statistically significant higher rate of HBV DNA $<300$ copies/mL at week 48 compared with adefovir (57\% versus $20 \%$, respectively, $P<0.0001)$. Entecavir also had higher rates of ALT normalization ( $63 \%$ versus $46 \%, P=0.0425)$ at week 48 . Rates of $\mathrm{HBeAg}$ loss (11\% versus 18\%), HBeAg seroconversion
(6\% versus $10 \%)$, and $\mathrm{HBs} A \mathrm{~g} \operatorname{loss}(5 \%$ versus $0 \%$ ) were not statistically different. As shown in the prior study, MELD scores improved by -2.6 in the entecavir group. Thirty-five percent of entecavir-treated patients had a reduction in their CTP score by two or more points at week 48 . Serious adverse events occurred in over $65 \%$ of both treatment groups, but the details of these events were not reported. Adverse events led to drug discontinuation in $7 \%$ of entecavir patients and $6 \%$ of adefovir patients. Further follow-up of these patients is needed to determine the effects of antivirals on patients' mortality and development of HCC. Although no major events were reported in these trials of entecavir in decompensated patients, caution is advised with its use in these fragile patients, as later case reports demonstrated fatal lactic acidosis.

There is little published information on entecavir in the post-liver transplant population. A single-center retrospective case-control study of 30 patients treated with entecavir compared with lamivudine showed that entecavir achieved undetectable HBsAg levels earlier than lamivudine (median 3 days versus 5 days). ${ }^{51}$ There were fewer HBV recurrences in the entecavir group ( $0 \%$ versus $11.1 \%$ in the lamivudine group), but cumulative survival rates after 30 months were similar in both groups (actuarial survival 81\%). Larger, prospective trials are needed in this population, but the limited data available are favorable. Given the long-term therapy necessary post-transplant, the low resistance rates associated with entecavir make it an attractive option for post-transplantation prophylaxis.

\section{HIV}

Entecavir has been studied in HIV-positive patients failing lamivudine-containing antiretroviral regimens. ${ }^{52}$ Ninety-five percent of these patients had lamivudine resistance at baseline, and the $1 \mathrm{mg}$ dose of entecavir was used. At 48 weeks, HBV DNA decreased by $4.2 \log$ copies $/ \mathrm{mL}$, and $8 \%$ of subjects had an undetectable HBV DNA. ALT normalization occurred in $37 \%$, and only $2 \%$ achieved $\mathrm{HBeAg}$ loss $/ \mathrm{HBeAg}$ seroconversion.

During clinical development, entecavir was not shown to have any activity against HIV. It therefore became the treatment of choice for HIV patients requiring treatment of HBV who did not meet criteria for antiretroviral therapy for HIV. Following its approval, reports of entecavir's effects on HIV replication and resistance were reported. ${ }^{53,54}$ In these reports, entecavir decreased HIV viral loads by about 1 log copies/mL. More sensitive in vitro assays using primary CD4+ T cells rather than transformed cell lines confirmed entecavir 
inhibition of HIV in the low nanomolar range..$^{53}$ In addition to effects on HIV viral load, entecavir also selected for the methionine to valine mutation at position $184(\mathrm{M} 184 \mathrm{~V})$ of the HIV reverse transcriptase, which is the signature mutation for HIV resistance to lamivudine. This occurred in three patients in the absence of any exposure to antiretrovirals. ${ }^{54}$ Because of these reports, entecavir is not recommended as monotherapy in HIV/HBV-coinfected patients who are not receiving a fully active antiretroviral regimen. Most recent HIV treatment guidelines from the United States Department of Health and Human Services ${ }^{55}$ and the International AIDS Society-USA ${ }^{55,56}$ list active chronic $\mathrm{HBV}$ as an indication for antiretroviral therapy in HIV patients, regardless of CD4 count or HIV viral load. This recommendation stems in part from these findings related to entecavir activity.

\section{Adverse effects}

During the Phase III trials of entecavir, there were no adverse effects of the drug that occurred more often than with the comparator drug. The most common adverse events were elevations in ALT, which were associated in all cases with reductions in HBV DNA. ${ }^{12,13}$ In most cases, these were selflimiting with continued treatment with entecavir. Among nucleoside-naïve $\mathrm{HBeAg}$-positive patients, ALT flares over twice baseline and $>10$ times upper limit of normal (ULN) occurred in 3\% of entecavir-treated patients, and ALT flares over twice baseline and more than five times ULN occurred in $10 \%$ of subjects. ${ }^{12}$ These numbers in naïve $\mathrm{HBeAg}$ - negative subjects were $<1 \%$ and $2 \%$, respectively. ${ }^{13}$ Discontinuation due to adverse events was $2 \%$ or less in both studies at 1 year. There were no unusual adverse effects during the Phase II and III trials that were concerning.

Experience with nucleoside analogs in the treatment of HIV demonstrated an association with certain drugs and lactic acidosis variably accompanied by hepatic steatosis, pancreatitis, peripheral neuropathy, and myopathy. The dideoxynucleotide analogs were particularly implicated (didanosine [ddI], zalcitabine [ddC]). Development of an investigational drug for HBV, fialuridine (FIAU), was halted after seven patients in a Phase II trial developed severe lactic acidosis after a minimum of 9 weeks of therapy. ${ }^{57}$ Five patients in the study died, and two survived only after emergent liver transplant. All seven had pancreatitis with severe lactic acidosis and hepatic failure. Histologic examination showed marked macro- and microvesicular steatosis and cholestasis. Mitochondrial anatomy was distinctly abnormal on electron microscopy. In part because of these clinical reports, all nucleos(t)ide analogs, including entecavir, carry a black-box warning against the occurrence of lactic acidosis and severe hepatomegaly with steatosis.

Further study into the mechanisms for both HIV antiretroviral and FIAU toxicity implicate damage to mitochondria as the reason for metabolic perturbation. ${ }^{58-60}$ In addition to inhibition of the viral polymerase, nucleoside analogs also inhibit the polymerase function of the human DNA polymerase- $\gamma$, which is responsible for replication of mitochondrial DNA. ${ }^{60}$ Depletion of mitochondrial DNA leads to mitochondrial dysfunction, as synthesis of proteins essential for oxidative phosphorylation is inhibited. Mutations in mitochondrial DNA and oxidative stress within the mitochondria may also contribute to this dysfunction. Electron leakage from the electron transport chain occurs with disruption of oxidative phosphorylation, increasing production of reactive oxygen species. ${ }^{60}$

In vitro studies of entecavir did not show any evidence for mitochondrial toxicity. ${ }^{61}$ Incubation of hepatoma HepG 2 cells with entecavir at 10 times maximum concentration produced no nonspecific cell cytotoxicity. Entecavir also did not affect extracellular lactate levels at the highest concentrations and durations tested. In assays of mitochondrial DNA, levels were not decreased on exposure to entecavir when compared with controls. Even at 100 times achievable concentrations in vivo, there were no changes in mitochondrial protein levels. Assays to assess DNA polymerase- $\gamma$ showed that entecavir did not utilize or inhibit function.

Despite these in vitro studies, postmarketing case reports of severe lactic acidosis during treatment with entecavir were published. ${ }^{62,63}$ In the first report, entecavir was used in combination with adefovir to treat a newly recognized HBV patient who developed a severe flare of hepatitis following chemotherapy for chronic lymphocytic leukemia. ${ }^{63}$ At the time of treatment initiation, his MELD score was approximately 24. His ALT was $3521 \mathrm{U} / \mathrm{L}$, AST $2853 \mathrm{U} / \mathrm{L}$, and bilirubin $20.9 \mathrm{mg} / \mathrm{dL}$. After 10 days of combination therapy, he presented with dyspnea, hypoxia, and profound metabolic lactic acidosis with a lactate level of $9.5 \mathrm{mEq} / \mathrm{L}, \mathrm{pH} 6.95$, and carbon dioxide level $8 \mathrm{mmol} / \mathrm{L}$. Entecavir and adefovir were discontinued. Despite aggressive measures, the patient expired within 24 hours of admission.

A second report describes a case series of 16 patients with advanced liver disease/decompensated cirrhosis treated with entecavir, of whom five developed lactic acidosis. ${ }^{62}$ In three cases, the syndrome was severe, and one of these cases died. Of the severe cases, lactic acidosis developed at 5 days, 8 days, and 8 months after initiation of entecavir. One of these cases was a post-liver transplant patient with 
recurrent HBV. Two additional patients had less severe lactic acidosis, which remained compensated. They developed symptoms at 4 and 31 days after starting entecavir therapy. In this series, all of the patients who developed lactic acidosis had an MELD score greater than 22 at the time of entecavir initiation. None of the patients whose MELD was lower than 18 developed lactic acidosis.

Neither of these reports provided histologic or microscopic evidence of mitochondrial damage. Only one patient in the second series was reported to have hepatic steatosis. Whether these reports of lactic acidosis represent manifestations of mitochondrial toxicity cannot be determined, although phenotypically they are suspicious. Of note, toxicity occurred much earlier in treatment than is usually seen with mitochondrial toxicity with other nucleoside analogs, suggesting a possible alternative mechanism for the lactic acidosis seen in these cases. These reports are heterogeneous, and a clear association with entecavir has not been well established. Entecavir is generally considered safe in decompensated cirrhosis, and both the American Association for the Study of Liver Diseases (AASLD) and European Association for the Study of the Liver (EASL) guidelines recommend it in this setting.

\section{Use of entecavir in clinical practice}

From the data discussed above, entecavir has been proven to potently suppress $\mathrm{HBV}$ replication with low rates of genotypic resistance even with long-term therapy in the nucleos(t)ide-naïve patient. In lamivudine-refractory patients, its success rate is compromised, illustrating the importance of drug sequencing when considering initial HBV therapy. Several professional societies around the world have made recommendations regarding initial therapy, taking these factors into consideration. The AASLD recommends entecavir or tenofovir as first-line oral agents for nucleos(t)ide-naïve patients, as both combine potency and low resistance rates. ${ }^{23}$ Recommendations from the EASL are concordant. ${ }^{64}$ The Asian Pacific Association for the Study of the Liver considers all agents to be first line, recognizing that the higher cost of entecavir and tenofovir may be prohibitive in some cases. ${ }^{65}$ Therefore, lamivudine remains a first-line option in this setting. Finally, the US Treatment Algorithm ${ }^{66}$ also recommends entecavir or tenofovir as first-line agents but describes a "road-map" approach, whereby therapy is modified at week 24 or 48 as determined by on-therapy virologic response. Patients who fail entecavir should be switched to tenofovir or tenofovir-emtricitabine according to this algorithm.
For patients who already express lamivudine resistance, entecavir is not the optimal salvage drug, as entecavir resistance develops more quickly. Telbivudine is also crossresistant, and patients failing this drug are also not good entecavir candidates. For patients failing lamivudine or telbivudine, tenofovir is a better alternative. For failures of adefovir or tenofovir, entecavir is predicted to maintain full activity and is a reasonable salvage choice.

\section{Summary}

The approval of entecavir in 2005 began a new era in the treatment of HBV where long-term virologic suppression was both realistic and safe. The low risk of entecavir resistance in naïve patients, in part due to its rapid and potent suppression of HBV DNA, makes it an optimal choice for the initial therapy of both $\mathrm{HBeAg}$-positive and $\mathrm{HBeAg-negative}$ patients. It requires three mutations to develop full resistance, the first of which is selected by lamivudine; hence, its activity is reduced in patients with genotypic lamivudine resistance. This is partly overcome by the use of a larger dose in lamivudine-refractory patients. There are few adverse effects associated with entecavir, although fatal cases of lactic acidosis have been reported with its use in decompensated cirrhotics, particularly when the MELD score exceeds 22 . It should be used with caution in this population. Its efficacy in HIV/HBV coinfected patients has been established, although it should not be used without a fully suppressive antiretroviral regimen, as anti-HIV activity has been described in vitro and in vivo. Its impact on end-stage liver disease and mortality has yet to be delineated, as it is yet too early to see the benefits of long-term viral suppression.

\section{Disclosure}

The author reports no conflicts of interest in this work.

\section{References}

1. Lavanchy D. Hepatitis B virus epidemiology, disease burden, treatment, and current and emerging prevention and control measures. JViral Hepat. 2004;11(2):97-107.

2. Hyams KC. Risks of chronicity following acute hepatitis B virus infection: a review. Clin Infect Dis. 1995;20(4):992-1000.

3. Yim HJ, Lok AS. Natural history of chronic hepatitis B virus infection: what we knew in 1981 and what we know in 2005. Hepatology. 2006; 43(2 Suppl 1):S173-S181.

4. Hadziyannis SJ, Papatheodoridis GV. Hepatitis B e antigen-negative chronic hepatitis B: natural history and treatment. Semin Liver Dis. 2006; 26(2):130-141.

5. Carman WF, Jacyna MR, Hadziyannis S, et al. Mutation preventing formation of hepatitis B e antigen in patients with chronic hepatitis B infection. Lancet. 1989;2(8663):588-591.

6. Hoofnagle JH, Doo E, Liang TJ, et al. Management of hepatitis B: summary of a clinical research workshop. Hepatology. 2007;45(4):1056-1075. 
7. Baraclude Package Insert. Wallingford, CT: Bristol-Myers Squibb. http://packageinserts.bms.com/pi/pi_baraclude.pdf. Accessed December 4, 2010.

8. Yamanaka G, Wilson T, Innaimo S, et al. Metabolic studies on BMS-200475, a new antiviral compound active against hepatitis B virus. Antimicrob Agents Chemother. 1999;43(1):190-193.

9. Seifer M, Hamatake RK, Colonno RJ, Standring DN. In vitro inhibition of hepadnavirus polymerases by the triphosphates of BMS-200475 and lobucavir. Antimicrob Agents Chemother. 1998;42(12):3200-3208.

10. Chang TT, Gish RG, Hadziyannis SJ, et al. A dose-ranging study of the efficacy and tolerability of entecavir in Lamivudine-refractory chronic hepatitis B patients. Gastroenterology. 2005;129(4):1198-1209.

11. De Man RA, Wolters LM, Nevens F, et al. Safety and efficacy of oral entecavir given for 28 days in patients with chronic hepatitis B virus infection. Hepatology. 2001;34(3):578-582.

12. Chang TT, Gish RG, de Man R, et al. A comparison of entecavir and lamivudine for HBeAg-positive chronic hepatitis B. $N$ Engl $J$ Med. 2006;354(10):1001-1010.

13. Lai CL, Shouval D, Lok AS, et al. Entecavir versus lamivudine for patients with $\mathrm{HBeAg-negative} \mathrm{chronic} \mathrm{hepatitis} \mathrm{B.} \mathrm{NEngl} \mathrm{J} \mathrm{Med.} \mathrm{2006;}$ 354(10):1011-1020.

14. Yao $\mathrm{G}, \mathrm{Chen} \mathrm{C}, \mathrm{Lu} \mathrm{W}$, et al. Efficacy and safety of entecavir compared to lamivudine in nucleoside-naive patients with chronic hepatitis B: a randomized double-blind trial in China. Hepatol Int. 2007;1(3):365-372.

15. Leung N, Peng CY, Hann HW, et al. Early hepatitis B virus DNA reduction in hepatitis $\mathrm{B}$ e antigen-positive patients with chronic hepatitis B: a randomized international study of entecavir versus adefovir. Hepatology. 2009;49(1):72-79.

16. Gish RG, Lok AS, Chang TT, et al. Entecavir therapy for up to 96 weeks in patients with $\mathrm{HBeAg}$-positive chronic hepatitis B. Gastroenterology. 2007;133(5):1437-1444.

17. Shouval D, Lai CL, Chang TT, et al. Relapse of hepatitis B in HBeAgnegative chronic hepatitis B patients who discontinued successful entecavir treatment: the case for continuous antiviral therapy. $J$ Hepatol. 2009;50(2):289-295.

18. Sherman M, Yurdaydin C, Sollano J, et al. Entecavir for treatment of lamivudine-refractory, $\mathrm{HBeAg}$-positive chronic hepatitis B. Gastroenterology. 2006;130(7):2039-2049.

19. Yao G, Zhou X, Xu D, et al. Entecavir for the treatment of lamivudinerefractory chronic hepatitis B patients in China. Hepatol Int. 2007;1(3): 373-381.

20. Suzuki F, Toyoda J, Katano Y, et al. Efficacy and safety of entecavir in lamivudine-refractory patients with chronic hepatitis B: randomized controlled trial in Japanese patients. J Gastroenterol Hepatol. 2008; 23(9):1320-1326.

21. Sherman M, Yurdaydin C, Simsek H, et al. Entecavir therapy for lamivudine-refractory chronic hepatitis B: improved virologic, biochemical, and serology outcomes through 96 weeks. Hepatology. 2008;48(1):99-108.

22. Yao GB, Xu DZ, Ren H, et al. Three years of continuous entecavir treatment in Chinese patients who had previously failed lamivudine: results from studies ETV-056 and ETV-050 (Abstract). Hepatology. 2008;48(Suppl 2):S267.

23. Lok AS, McMahon BJ. Chronic hepatitis B: update 2009. Hepatology. 2009;50(3):661-662.

24. Chang TT, Lai CL, Kew Yoon S, et al. Entecavir treatment for up to 5 years in patients with hepatitis B e antigen-positive chronic hepatitis B. Hepatology. 2010;51(2):422-430.

25. Lai CL, Chien RN, Leung NW, et al. A one-year trial of lamivudine for chronic hepatitis B. Asia Hepatitis Lamivudine Study Group. $N$ Engl $J$ Med. 1998;339(2):61-68.

26. Dienstag JL, Perrillo RP, Schiff ER, et al. A preliminary trial of lamivudine for chronic hepatitis B infection. $N$ Engl $J$ Med. 1995;333(25):1657-1661.

27. Marcellin P, Chang TT, Lim SG, et al. Adefovir dipivoxil for the treatment of hepatitis B e antigen-positive chronic hepatitis B. $N$ Engl J Med. 2003;348(9):808-816.
28. Zeng M, Mao Y, Yao G, et al. A double-blind randomized trial of adefovir dipivoxil in Chinese subjects with $\mathrm{HBeAg}$-positive chronic hepatitis B. Hepatology. 2006;44(1):108-116.

29. Chan HL, Heathcote EJ, Marcellin P, et al. Treatment of hepatitis B e antigen positive chronic hepatitis with telbivudine or adefovir: a randomized trial. Ann Intern Med. 2007;147(11):745-754.

30. Hou J, Yin YK, Xu D, et al. Telbivudine versus lamivudine in Chinese patients with chronic hepatitis B: Results at 1 year of a randomized, double-blind trial. Hepatology. 2008;47(2):447-454.

31. Lai CL, Gane E, Liaw YF, et al. Telbivudine versus lamivudine in patients with chronic hepatitis B. N Engl J Med. 2007;357(25):2576-2588.

32. Marcellin P, Heathcote EJ, Buti M, et al. Tenofovir disoproxil fumarate versus adefovir dipivoxil for chronic hepatitis B. $N$ Engl J Med. 2008; 359(23):2442-2455.

33. Hadziyannis SJ, Tassopoulos NC, Heathcote EJ, et al. Adefovir dipivoxil for the treatment of hepatitis $\mathrm{B}$ e antigen-negative chronic hepatitis B. N Engl J Med. 2003;348(9):800-807.

34. Liaw YF, Chien RN, Yeh CT, et al. Acute exacerbation and hepatitis B virus clearance after emergence of YMDD motif mutation during lamivudine therapy. Hepatology. 1999;30(2):567-572.

35. Fung SK, Andreone P, Han SH, et al. Adefovir-resistant hepatitis B can be associated with viral rebound and hepatic decompensation. J Hepatol. 2005;43(6):937-943.

36. Leung NW, Lai CL, Chang TT, et al. Extended lamivudine treatment in patients with chronic hepatitis B enhances hepatitis B e antigen seroconversion rates: results after 3 years of therapy. Hepatology. 2001;33(6):1527-1532.

37. Tenney D, Pokornowski K, Rose RE, et al. Entecavir maintains a high genetic barrier to HBV resistance through 6 years in naive patients (Abstract). Hepatology. 2009;50(Suppl 2):S10.

38. Tenney DJ, Rose RE, Baldick CJ, et al. Long-term monitoring shows hepatitis B virus resistance to entecavir in nucleoside-naive patients is rare through 5 years of therapy. Hepatology. 2009;49(5):1503-1514.

39. Hadziyannis SJ, Tassopoulos NC, Heathcote EJ, et al. Long-term therapy with adefovir dipivoxil for $\mathrm{HBeAg}$-negative chronic hepatitis B. N Engl J Med. 2005;352(26):2673-2681.

40. Hadziyannis SJ, Tassopoulos NC, Heathcote EJ, et al. Long-term therapy with adefovir dipivoxil for $\mathrm{HBeAg}$-negative chronic hepatitis $\mathrm{B}$ for up to 5 years. Gastroenterology. 2006;131(6):1743-1751.

41. Snow-Lampart A, Kitrinos K, Chappell BJ, et al. No resistance to tenofovir disoproxil fumarate (TDF) detected following 192 weeks of treatment in subjects mono-infected with chronic hepatitis B virus (Abstract). Hepatology. 2010;52(Suppl 1):977A.

42. Liaw YF, Gane E, Leung N, et al. 2-Year GLOBE trial results: telbivudine is superior to lamivudine in patients with chronic hepatitis B. Gastroenterology. 2009;136(2):486-495.

43. Tipples GA, Ma MM, Fischer KP, et al. Mutation in HBV RNA-dependent DNA polymerase confers resistance to lamivudine in vivo. Hepatology. 1996;24(3):714-717

44. Angus P, Vaughan R, Xiong S, et al. Resistance to adefovir dipivoxil therapy associated with the selection of a novel mutation in the HBV polymerase. Gastroenterology. 2003;125(2):292-297.

45. Borroto-Esoda K, Miller MD, Arterburn S. Pooled analysis of amino acid changes in the HBV polymerase in patients from four major adefovir dipivoxil clinical trials. J Hepatol. 2007;47(4): 492-498.

46. Tenney DJ, Levine SM, Rose RE, et al. Clinical emergence of entecavir-resistant hepatitis $\mathrm{B}$ virus requires additional substitutions in virus already resistant to Lamivudine. Antimicrob Agents Chemother. 2004;48(9):3498-3507.

47. Baldick CJ, Eggers BJ, Fang J, et al. Hepatitis B virus quasispecies susceptibility to entecavir confirms the relationship between genotypic resistance and patient virologic response. $J$ Hepatol. 2008;48(6): 895-902.

48. Schiff E, Simsek H, Lee WM, et al. Efficacy and safety of entecavir in patients with chronic hepatitis B and advanced hepatic fibrosis or cirrhosis. Am J Gastroenterol. 2008;103(11):2776-2783. 
49. Shim JH, Lee HC, Kim KM, et al. Efficacy of entecavir in treatment-naive patients with hepatitis B virus-related decompensated cirrhosis. J Hepatol. 2010;52(2):176-182.

50. Liaw YF, Raptopoulou-Gigi M, Chienquer H, et al. Efficacy and safety of entecavir versus adefovir in chronic hepatitis B patients with evidence of hepatic decompensation (Abstract). Hepatology. 2009;50(Suppl 4): $505 \mathrm{~A}$.

51. Xi ZF, Xia Q, Zhang JJ, et al. The role of entecavir in preventing hepatitis B recurrence after liver transplantation. J Dig Dis. 2009;10(4): 321-327.

52. Pessoa MG, Gazzard B, Huang AK, et al. Efficacy and safety of entecavir for chronic $\mathrm{HBV}$ in $\mathrm{HIV} / \mathrm{HBV}$ coinfected patients receiving lamivudine as part of antiretroviral therapy. AIDS. 2008;22(14):1779-1787.

53. McMahon MA, Jilek BL, Brennan TP, et al. The HBV drug entecavir: effects on HIV-1 replication and resistance. $N$ Engl J Med. 2007; 356(25):2614-2621.

54. Sasadeusz J, Audsley J, Mijch A, et al. The anti-HIV activity of entecavir: a multicentre evaluation of lamivudine-experienced and lamivudine-naive patients. AIDS. 2008;22(8):947-955.

55. Department of Health and Human Services. Guidelines for the use of antiretroviral agents in HIV-1-infected adults and adolescents. Office of AIDS Research Advisory Council (OARAC). December 1, 2009. http:// aidsinfo.nih.gov/contentfiles/AdultandAdolescentGL.pdf. Accessed December 12, 2010.

56. Hammer SM, Eron JJ Jr, Reiss P, et al. Antiretroviral treatment of adult HIV infection: 2008 recommendations of the International AIDS Society-USA panel. JAMA. 2008;300(5):555-570.

57. McKenzie R, Fried MW, Sallie R, et al. Hepatic failure and lactic acidosis due to fialuridine (FIAU), an investigational nucleoside analogue for chronic hepatitis B. N Engl J Med. 1995;333(17):1099-1105.
58. Brinkman K, ter Hofstede HJ, Burger DM, et al. Adverse effects of reverse transcriptase inhibitors: mitochondrial toxicity as common pathway. AIDS. 1998;12(14):1735-1744.

59. Colacino JM. Mechanisms for the anti-hepatitis B virus activity and mitochondrial toxicity of fialuridine (FIAU). Antiviral Res. 1996;29(2-3):125-139.

60. Lewis W, Day BJ, Copeland WC. Mitochondrial toxicity of NRTI antiviral drugs: an integrated cellular perspective. Nat Rev Drug Discov. 2003;2(10):812-822.

61. Mazzucco CE, Hamatake RK, Colonno RJ, Tenney DJ. Entecavir for treatment of hepatitis $\mathrm{B}$ virus displays no in vitro mitochondrial toxicity or DNA polymerase gamma inhibition. Antimicrob Agents Chemother. 2008;52(2):598-605.

62. Lange CM, Bojunga J, Hofmann WP, et al. Severe lactic acidosis during treatment of chronic hepatitis B with entecavir in patients with impaired liver function. Hepatology. 2009;50(6):2001-2006.

63. Cohen SM, Levy RM, Jovanovich JF, Ahn J. Fatal lactic acidosis associated with the use of combination oral medications to treat reactivation of hepatitis B. J Clin Gastroenterol. 2009;43(10):1008-1010.

64. European Association for the Study of the Liver. EASL clinical practice guidelines: management of chronic hepatitis B. $J$ Hepatol. 2009;50(2):227-242.

65. Liaw YF, Leung N, Kao JH, et al. Asian-Pacific consensus statement on the management of chronic hepatitis B: a 2008 update. Hepatol Int. 2008;2:263-283.

66. Keeffe EB, Dieterich DT, Han SH, et al. A treatment algorithm for the management of chronic hepatitis B virus infection in the United States: 2008 update. Clin Gastroenterol Hepatol. 2008;6(12):1315-1341.
Infection and Drug Resistance

\section{Publish your work in this journal}

Infection and Drug Resistance is an international, peer-reviewed openaccess journal that focuses on the optimal treatment of infection (bacterial, fungal and viral) and the development and institution of preventive strategies to minimize the development and spread of resistance. The journal is specifically concerned with the epidemiology of antibiotic

\section{Dovepress}

resistance and the mechanisms of resistance development and diffusion in both hospitals and the community. The manuscript management system is completely online and includes a very quick and fair peerreview system, which is all easy to use. Visit http://www.dovepress.com/ testimonials.php to read real quotes from published authors. 